\title{
Top Ten Developments in Studies on Chinese Humanities in 2018
}

\author{
Translated by Connie Rosemont
}

Chinese humanities scholarship has been robust in recent years and is now going through profound changes. To stay abreast of these new developments and trends, and to promote continued flourishing of humanities scholarship and public awareness, the Journal of Literature, History, and Philosophy [Wen shi zhe 文史哲] and China Reader Weekly [Zhonghua dushu bao 中華讀書報] jointly hosted the selection of the “2018 Top Ten Humanities Study Topics” for the fifth consecutive year. This year's selection includes:

\section{Humanities and Social Sciences Circles Solemnly Commemorated the Fortieth Anniversary of China's Reform and Opening Up. A Sense of National Self-Awareness Has Become a Common Starting Point in Recent Scholarly Pursuits}

Since 1949, two paradigm shifts have taken place in Chinese humanities and social sciences studies. The first dramatic transformation began in 1949, when the Republic of China became the People's Republic of China. The second shift began in 1978, when the framework of modernization replaced the framework of class theory. In both scope and depth, the second shift can be considered a second opening up. In light of this consensus, the humanities and social sciences community solemnly commemorated the fortieth anniversary in a variety of ways, using the opportunity to review and summarize forty years of achievement across disciplines. At colleges and universities around the country, the departments of political science, economics, law, literature, philosophy, history, and so on convened their own thematic conferences. Many scholarly publications dedicated columns to the topic, and numerous scholars wrote special articles. Beijing University and the Commercial Press jointly produced a book series titled "Chinese Social Sciences and Forty Years of Reform and Opening Up." 
Academic circles widely consider the past forty years of Chinese scholarship and its trend toward opening up a period of great growth. After several decades of building knowledge systems, scholarly networks, and new academic disciplines, scholars have re-established an open-minded Chinese academic community that is integrated into international circles and moving forward as a group. More research has made increasingly clear the limits of Western-language interpretations of Chinese experiences and issues. The academic community thus is consciously exploring domestic phenomena with domestic theories. The logical next step for Chinese scholars is an evolution of this focus on a "Chinese subjective consciousness," allowing them to stand tall among their peers in global scholarship. Just as importantly, it provides solid academic support for the revitalization of Chinese culture.

\section{Academic Circles Took the Occasion of the 2ooth Anniversary of Marx's Birth and the 17oth Anniversary of the Publication of the Communist Manifesto to Renew Conversations on the Significance of Marxism in Contemporary China and the World}

The 20oth anniversary of Karl Marx's birth and the 17oth anniversary of the publication of the Communist Manifesto were in 2018. Using this occasion, Chinese scholars published a host of research from new vantage points and with greater dimensionality, showing that Marx's diagnosis of the pathology of capitalism and his prediction of the likely path and prospects for human emancipation created opportunities for us to consciously grapple with "world history" and to transcend a narrow vision of the nation-state.

Issues related to global environmental degradation and serious inequalities created by a wide gap between rich and poor have created unprecedented and grave challenges for human survival and development. How to treat and manage the duality of "capitalist power" and the paradoxical consequences of its shortcomings are some of the most pressing questions of our times. At the same time, new breakthroughs in science and technology continue to profoundly reshape how people live. The result of any one-time historical technological advance could introduce the possibility of an unprecedented transformation, which forces us to consider the future fate of humanity in terms of forming a new culture.

Faced with this unprecedented and rigorous test, the academic community has recognized that Marx's theories are still a guiding force: As part of the continuous process of explaining Chinese history and society, Marxist doctrine has shaped the course of China. It has changed the fate of the Chinese 
people, creating socialism with Chinese characteristics. For the Chinese, this is undoubtedly of enormous spiritual value and constitutes an incisive and clear framework for understanding our history. It has also become an intellectual pathfinder with which to plan for the future.

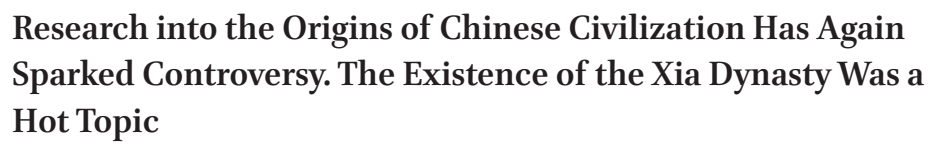

In May 2018, the State Council Information Office issued the research summary "The Project to Discover the Source of Chinese Civilization," in which it proposed that areas surrounding the Yellow River, the Yangtze River, and the Xiliao River were already part of the ancient period of Chinese civilization before the establishment of the Xia dynasty. At the same time, important discoveries of early settlements, such as Lingjiatan in Anhui Province, Liangzhu in Zhejiang Province, Taosi in Shanxi Province, and the Stone Loess mounds in Shaanxi Province, have allowed archaeologists and historians to reconsider existing research perspectives on the origins of Chinese civilization. The question of whether the Xia dynasty existed again became an active topic of scholarly debate.

Sun Qingwei published a monograph, Toward an Archeological Reconstruction of the Xia Dynasty as History, in which he explicitly argued that research into Xia culture requires attention to the methodologies used to discern it and not to acts of "discovery." Using a comparative cultural archaeology approach, he argues that the existence of Xia culture can be assessed without excavating textual material. As soon as this theory was published, it caused immediate and widespread dispute in academic circles. Opponents maintain that an insufficient archeological record and data can only make the existence of Xia culture unverifiable; it cannot be proved one way or the other. Other scholars proposed that nationalist sentiments and strong notions of "making the past serve the present" lay behind the monograph, an approach that was not a neutral position of scientific inquiry. At the same time, some scholars argued that the standards used by Western scholars to determine the origins of culture - text and smelting technology - do not correspond to the facts of Chinese history. Probing Xia culture is a responsibility that Chinese archaeology must shoulder. What archaeologists must do is use the approach of "believing antiquity" to link and integrate special characteristics of remote antiquity, thereby "interpreting antiquity." Whether consensus on this issue will be reached in the near future remains to be seen. 


\author{
Ethical Consensus in Science and Technology Developments \\ Takes a Pounding: “Gene Editing for Infants" Gives Rise to \\ Troubling Considerations about the Fate of Humanity
}

In 2018, the world's first "gene-edited babies" were born in Shenzhen. As soon as the news was announced, 122 scientists immediately published a joint declaration strongly condemning the project's lack of a proper biomedical ethics review. They pointed out that human experiments in gene editing risk "missing the mark" and could have a negative impact on society. They called on relevant departments and research units to quickly revise legislation and put into effect strict oversight regulations. The Ministry of Science and Technology, the Chinese Academy of Sciences, the China Association of Science and Technology, and other organizations also responded, issuing a formal statement to ban such practices, expressing resolute opposition, and asking that the issue be addressed in accordance with relevant Chinese laws and rules.

The experiment was widely criticized because the current state of technology still has shortcomings and drawbacks, and any "improvement" in human genetics is extremely dangerous and irresponsible. Gene editing has an irrevocable quality. If an error occurred in which the editing "missed the mark," unforeseen danger is introduced for the object of the experiment and potentially for the entire gene pool, threatening all of humanity. When emerging technology is rapidly developed that can alter the human body, with the further possibility of reshaping human culture, only by reinforcing and safeguarding humanistic constraints and preserving sufficient awe for natural evolution can we maximize the ultimate goal of using technology to benefit humankind.

\title{
With the Deaths of Rao Zongyi and Jacques Gernet, France Loses Two Giants and Its Central Role in European Sinological Discourse
}

In 2018, the renowned sinologists Rao Zongyi and Jacques Gernet [Xie Henai] both died. Rao was the last of his generation of venerable classical Chinese scholars, with close ties to French sinological circles. Gernet was France's most authoritative sinologist, presiding over French sinology for a long time. In one sense, the passing of these two giants in the field represents the end of the central position that France has held in continental European sinology.

Since 1814, when the Collège de France established its first sinology chair, the French sinology world has produced generation after generation of exceptional talent. Primarily using philology and historical linguistics, scholars produced brilliant works on the history of Inner Asia, religious history, Dunhuang 
studies, and numerous other topics. Early twentieth-century sinologists, such as Edouard Chavannes and Paul Pelliot, have left colorful and vivid writings on the history of modern Chinese scholarship. Both Rao and Gernet carried on the efforts of Chavanne's disciple Paul Demiéville [Dai Miwei], to extend and deepen French sinological research. But after World War II, especially since the 1970 s and 1980s, the purview of European sinology gradually narrowed, gradually ceding international leadership to the American social sciences approach to sinological studies. Rao and Gernet were the last blush of the sunset of exceptional European continental sinology. Their departure is not only a great loss to international sinology but also marks the fading of a once-brilliant tradition of continental European sinology.

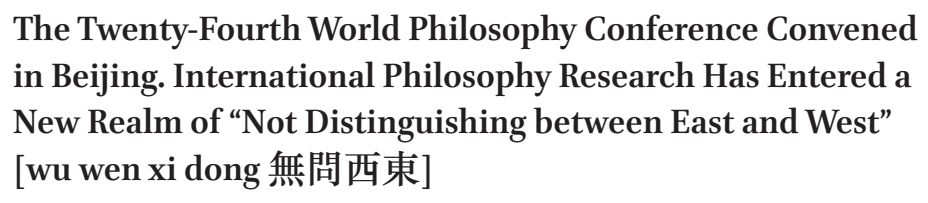

Western philosophy could be called the lead actor on the stage of world philosophy. In the seventeenth century, European Enlightenment thinkers had a brief fascination with Chinese culture, proceeding from a desire to find spiritual alliances and role models. But this situation did not last long, and soon after the Enlightenment had taken firm root, both [Immanuel] Kant and [G. W. F.] Hegel quickly concluded, "There is no philosophy in the East." Beginning in the mid-nineteenth century, in the wake of the introduction of Western scholarship, the Chinese academic world adopted Western philosophy's methods of categorization and analysis for Chinese philosophy, which seriously altered traditional classical studies and their subfields. But voices of dissent persisted. Since the turn of the twenty-first century, with the rise of culturally subjective consciousness in China, the Chinese academic community has engaged in reflection and debate about the "legitimacy of Chinese philosophy." To safeguard the "special characteristics" of traditional Chinese thought, some theorists have advocated abandoning the entire structure of Chinese philosophy studies. The future relationship between philosophy and "Chinese studies" has become an important concern in the international academic community.

The twenty-fourth World Philosophy Conference was held in Beijing in August 2018, offering a rare opportunity to discuss that question. The conference put special emphasis on the globalization of philosophical research and the need to include multifaceted forms of philosophical inquiry from all types of thinkers from different cultures, past and present. Participants relied on the 
Chinese tradition of "becoming a more complete person through studying" [Xueyi chengren 學以成人] to consider major topics in both Anglo-analytical and European continental philosophy. This approach injected new connotations of "multiculturalism and all traditions" into the discussions, with the suggestion that world philosophy research might enter a new realm of "[not distinguishing between] East and West." Unearthing Ancient Chinese Science and Technology Traditions

The success of the Mozi satellite intercontinental quantum experiment mission attracted international attention. Mozi, a scientific genius who made remarkable contributions more than two thousand years ago to the fields of optics, acoustics, mechanics, geometry, and others, has once again become the focus of popular attention. When the National Library Press published the book Mozi, every domestic publishing house also promoted some aspect of Mozi's works, and Mozi Salons-a popular scientific lecture series- took off. The twentieth-century British scholar Joseph Needham asked, "Why didn't China have a scientific revolution in the modern era [given its ancient scientific accomplishments]?" Needham's question has long put China scholars through their paces and spurred deep reflection and sharp critiques of the relationship between Chinese tradition, its knowledge systems, and scientific culture. In the past forty years, giant strides in Chinese science and technology have permitted China's increasing prominence as an innovative country. These strides indicate the intrinsic power in Chinese culture and the reignition of its scientific spirit and craftsmanship, as represented in Mohism. Widespread interest has been reawakened in all parts of society about ancient Chinese science and technology traditions.

The Centenary of the Publication of "A Madman's Diary"; "the Political Lu Xun" Is Again Presented Before World Audiences

In May 1918, New Youth published Lu Xun's short story, "A Madman's Diary" [also called "The Diary of a Madman"], which was seen as a penetrating exposé of the "cannibalistic" nature of the clan system and its feudal code of ethics. On the occasion of the hundredth anniversary of its publication, academic circles organized numerous activities from diverse multidisciplinary perspectives and undertook a new assessment of the distinctively critical tradition of "literary 
politics" pioneered by Lu Xun. The value of his political and literary legacy received new recognition and a fresh appraisal.

In the second half of the twentieth century, Lu Xun's image changed from the canonized "Lu Xun the politician" to the secular "Lu Xun the man." But since 2000, Chinese humanities circles have made a directional shift. A resurgence has occurred in traditional Chinese culture, most notably in the exploration of Confucianism. Against the backdrop of cultural regeneration and the fight to preserve tradition, research on Lu Xun is no longer solely the object of modern and contemporary literary studies. Academic circles refocused significant attention on "Lu Xun the politician," particularly on the multifaceted connections Lu Xun made between his thinking and social reality. This was the result of internal logical developments in Lu Xun scholarship, and it was also a sign of reflection in academic circles on the evolution of contemporary society. Conversations about "Lu Xun the man" and "Lu Xun the politician" present a more prudent and mature review of the coupling of our literary and political traditions and show the potential for reactivating Lu Xun's intellectual legacy in a new era.

\section{9 Hou Xudong's New Work, Favoritism: the Monarch's Relationship
with Subjects Based on Private Trust and the Unfolding of Western
Han History, Challenges Existing Models. "New Political History"
Research Is Flourishing}

Political history and research on institutional systems have been the backbone of domestic ancient history studies for the past forty years. Study of the history of traditional political systems has emphasized the interpretation of political events and the reconstruction of underlying systems. Its tremendous achievements are accompanied by stereotypes. Times shift, and trends change, and with the recent popularity and prevalence of new historiographical research, the research orientation of the history of traditional political systems has run up against ongoing criticism and inquiry, to the point that the question "Does political history have a future?" has been raised.

In 2018, Hou Xudong published his new work, Favoritism: The Monarch's Relationship with Subjects Based on Private Trust and the Unfolding of Western Han History [Chong: Xin-Ren xing junchen guanxi yu Xihan lishi de zhankai 寵: 信一任型君臣關係與西漢歷史的展開]. This book expounds the author's concept of "daily rule" - which draws on cultural anthropology methods and takes a "relationship cycle" perspective- to interpret Western Han political history. In the preface, the author explicitly says he wants to "say goodbye to the linear 
historical view," pointing out that prior research has been oriented toward historical teleology, the use of a linear historical perspective that is essentially old wine in new bottles. He advocates that researching the complex interactions between individuals and institutions enables the surmounting of the "rules" and "inevitabilities" of outdated paradigms and escape the research confines of traditional political systems history.

The publication of this book comes at the same time as a recent vogue for other new directions in ancient political history research, such as "living institutional history," "political culture," and "historical criticism." This has all provided new models and examples for political history studies to dismantle old paradigms, indicating that new political history research might emerge from the great number of new cultural history studies.

The "Rural Revitalization Strategy" Comprehensively Begins. Liang Shuming's “Zouping Experiment” Again Receives Attention

The "rural revitalization strategy" was initiated in 2018, with the goals of building new rural governance systems, improving rural social organizations, and reforming rural customs. This coincided with the thirtieth anniversary of the death of Liang Shuming. His “Zouping experiment” [Zouping shiyan 鄒平實驗] and the theoretical concepts behind his rural reconstruction movement became a hot topic in academic circles. People hope that lessons and resources can be drawn from Liang's experiences that will be beneficial for today's rural revitalization.

Liang Shuming saw the collapse of village society as a microcosm of the collapse of Chinese civilization. The ultimate goal of rural construction was to revitalize Chinese culture. Revitalizing Chinese culture and rebuilding Chinese society required "putting effort into the countryside" and reviving rural education and customs. The Zouping experiment ended early because of the onset of the Sino-Japanese War, but its achievements and way of thinking inspired later scholars. Some scholars have said that Liang's rural construction experiment offered cultural self-salvation in the context of a traditional society on the verge of collapse. The context of today's rural revitalization, by contrast, is a vigorous promotion of the best of traditional culture. It is both cultural legacy and innovation, which share common approaches on how rural communities can be revitalized. We are eighty years away from Liang's Zouping experiment, and social structure has changed enormously. At the end of the day, his theories and practical applications still have reference value for us today, more yet to be explored. 